ACCEPTED MANUSCRIPT

\title{
Contact Resistance Reduction of ZnO Thin Film Transistors (TFTs) with Saw-Shaped Electrode
}

To cite this article before publication: Woojin Park et al 2018 Nanotechnology in press https://doi.org/10.1088/1361-6528/aac4b9

\section{Manuscript version: Accepted Manuscript}

Accepted Manuscript is "the version of the article accepted for publication including all changes made as a result of the peer review process, and which may also include the addition to the article by IOP Publishing of a header, an article ID, a cover sheet and/or an 'Accepted

Manuscript' watermark, but excluding any other editing, typesetting or other changes made by IOP Publishing and/or its licensors"

This Accepted Manuscript is @ 2018 IOP Publishing Ltd.

During the embargo period (the 12 month period from the publication of the Version of Record of this article), the Accepted Manuscript is fully protected by copyright and cannot be reused or reposted elsewhere.

As the Version of Record of this article is going to be / has been published on a subscription basis, this Accepted Manuscript is available for reuse under a CC BY-NC-ND 3.0 licence after the 12 month embargo period.

After the embargo period, everyone is permitted to use copy and redistribute this article for non-commercial purposes only, provided that they adhere to all the terms of the licence https://creativecommons.org/licences/by-nc-nd/3.0

Although reasonable endeavours have been taken to obtain all necessary permissions from third parties to include their copyrighted content within this article, their full citation and copyright line may not be present in this Accepted Manuscript version. Before using any content from this article, please refer to the Version of Record on IOPscience once published for full citation and copyright details, as permissions will likely be required. All third party content is fully copyright protected, unless specifically stated otherwise in the figure caption in the Version of Record.

View the article online for updates and enhancements. 


\section{Contact Resistance Reduction of ZnO Thin Film}

\section{Transistors (TFTs) with Saw-Shaped Electrode}

\section{Woojin Park ${ }^{1,4}$, Sohail. F. Shaikh ${ }^{1,4}$, Jung-Wook Min², Sang Kyung Lee ${ }^{3}$,}

Byoung Hun Lee ${ }^{3}$ and Muhammad M. Hussain ${ }^{1, *}$

${ }^{1} \mathrm{mmh}$ Labs

${ }^{2}$ Photonics Lab

Electrical Engineering, Computer Electrical Mathematical Science and Engineering Division 4700 King Abdullah University of Science and Technology (KAUST),

Thuwal 23955-6900, Saudi Arabia

${ }^{3}$ Canter for Emerging Electronic Devices and Systems, School of Material Science and Engineering

Gwangju Institute of Science and Technology (GIST),

Gwangju 61005, South Korea

${ }^{4}$ Authors contributed equally to the present work.

*Authors to whom any correspondence should be addressed.

E-mail: muhammadmustafa.hussain@kaust.edu.sa 


\begin{abstract}
We report a saw-shaped electrode architecture $\mathrm{ZnO}$ thin film transistor (TFT) for effectively increase channel width. Such a saw-shaped electrode has $\sim 2$ times longer contact line at the contact metal/ZnO channel junction. We experimentally observed an enhancement in the output drive current by $50 \%$ and reduction in the contact resistance by over $50 \%$, when compared to a typical shaped electrode ZnO TFT consuming the same chip area. This performance enhancement is attributed to extension of channel width. This technique can contribute to device performance enhancement and especially reduction in the contact resistance which is a serious challenge.
\end{abstract}

Keywords: Zinc Oxide (ZnO); Thin Film Transistor; Contact Resistance; Saw-shaped Electrode 


\section{Introduction}

Zinc oxide $(\mathrm{ZnO})$, an amorphous oxide semiconductor is prominent for its low cost, low temperature process capabilities, non-toxicity, high performance, and flexibility/transparency [110]. $\mathrm{ZnO}$ has been extensively explored for various applications, such as nano-generators, sensors, flexible devices, memory devices, and logic circuits [11-16]. In particular, $\mathrm{ZnO}$ has been widely investigated for back-plane thin film transistor (TFT) enabling display technology. When compared to amorphous silicon (a-Si), which is used for low-resolution display, $\mathrm{ZnO}$ has benefits in terms of higher saturation mobility, showing a similar performance that of poly silicon TFT [17].

However, to translate its potential for display industry as backplane transistor, it is important to increase the driving current value to improve the device performance for a highspeed circuit design. So far, it is well-known that channel length $\left(\mathrm{Lg}_{\mathrm{g}}\right)$ scaling is one of the most effective approaches to increase drive current. This correlation can be understood by the transit frequency, $\mathrm{f}_{\mathrm{T}}$, which can be defined by the following equation for a digital circuit design [9].

$$
f_{T}=\frac{g_{m}}{2 \times \pi \times C_{o x}} \sim \frac{\mu \times\left(V_{G S}-V_{T}\right)}{2 \times \pi \times L_{g}^{2}}
$$

$\mathrm{C}_{\mathrm{ox}}$ is the gate oxide capacitance, $\mathrm{L}_{\mathrm{g}}$ is the gate length, $\mu$ is the field-effect mobility, and $\left(\mathrm{V}_{\mathrm{GS}}-\mathrm{V}_{\mathrm{T}}\right)$ is the gate overdrive voltage of the TFT. This empirical correlation shows that the development of semiconductor industry has been mostly driven by geometrical $\mathrm{Lg}_{\mathrm{g}}$ scaling. In turn, not only increases circuit integration, but also improves circuit operation speed by $\tau_{\text {delay }}=\mathrm{CV} / \mathrm{I}$. Reduction in $\mathrm{Lg}_{\mathrm{g}}$ is possible with several ways including a top-down lithographic scaling and a vertical channel TFT structure without a lithography process [18-19]. However, as $\mathrm{L}_{\mathrm{g}}$ scaling approaches to the sub-100 $\mathrm{nm}$ regime, industry has confronted technological barriers such as serious gate leakage current. $\mathrm{L}_{\mathrm{g}}$ scaling can induce $\mathrm{V}_{\mathrm{TH}}$ shift, which can result into a high off-state 
current, IoFF, and can degrade output swing and thus increases the power consumption [20]. Because of these problems, it may be effective to consider other factors besides $\mathrm{L}_{\mathrm{g}}$ scaling to improve device performance. For example, reduction in contact resistance can be expected to improve device performance while avoiding the short channel effect (SCE), which is a problem arising from device scaling.

Recently, reduction in contact resistance is an important concern for device performance improvements with scaling in the conventional Silicon devices and nano-material based transistors including ZnO TFTs [21-23]. Since the nano-device has a contact system between the metal electrode and the semiconductor that generates the Schottky-barrier, the device operation can greatly be influenced by the state of the contact region. This indicates that efforts to reduce contact resistance are more effective in nano-material based transistors including $\mathrm{ZnO}$ TFTs. Therefore, reduction in contact resistance can be suggested as an effective approach to achieve higher drive current, avoiding serious current leakage problems.

Here we suggest a structural reconfiguration of contact electrodes into saw-shaped to increase effective channel width. However, the idea of interdigitated electrodes has been employed mostly for enhancement of photo-generation in photo-detectors without investigating an advantage of contact resistance reduction [24]. Compared to the typical electrode, the sawshaped electrode increases channel width by nearly 2 times without consuming extra chip area. As mentioned above, $\mathrm{ZnO}$ TFT is one of Schottky-barrier type transistors, meaning that overall device operation can be determined by the contact region. Electric field from the gate terminal has strong influences on the extended contact line with the saw-shaped electrode, enhancing gate field electrostatics. As a result, contact resistance was reduced by over 2 times, which in turn drive current increases $\sim 50 \%$ per unit chip area without more device area consumption. 


\section{Experimental details}

A $\mathrm{P}^{++} \mathrm{Si} / 300 \mathrm{~nm} \mathrm{SiO} 2$ wafer was prepared through a chemical cleaning (mixture of Aceton, IPA, DI water). Atomic layer deposition (ALD) was used to deposit $\mathrm{ZnO}$ film (300 cycles). The source is a precursor combination of diethylzinc as metal-precursor and pure oxygen. To observe the $\mathrm{ZnO}$ channel surface, scanning electron microscope (SEM, NovaNano) and atomic force microscopy (AFM, SPM-5500) were used. $\mathrm{ZnO}$ film root means square (RMS) and thickness was estimated as $\sim 3.2 \mathrm{~nm}$ and $\sim 58 \mathrm{~nm}$ with an AFM measurement. Raman spectroscopy (ARAMIS, laser wavelength: $473 \mathrm{~nm}, 50 \mathrm{~mW}$ ) was used to evaluate the optical characteristics of the transferred representative $\mathrm{ZnO}$ film. Photoluminescence (PL) measurement (ARAMIS, laser wavelength: $325 \mathrm{~nm}$ ) was conducted to estimate the band-gap and defect-level for $\mathrm{ZnO}$ film. Photolithography and chemical etching with buffered oxide etchant was conducted to define $\mathrm{ZnO}$ channel. Photolithography process was conducted again to form source and drain electrodes. Physical vapor deposition (PVD) was done with e-beam evaporator to deposit metal electrode. Titanium (Ti) was used as contact metal since it has small band offset with $\mathrm{ZnO}$ channel. Finally, device fabrication was completed with a lift-off process, followed by thermal annealing at $200{ }^{\circ} \mathrm{C}$ for an hour in a vacuum chamber. Transfer/output characterization and transmission line measurement (TLM) of ZnO TFTs were done using a Keithley 4200-SCS semiconductor parameter analyzer at room temperature in an ambient air.

\section{Results and discussion}

We studied the physical properties of a $\mathrm{ZnO}$ film using atomic force microscopy (AFM), Raman, photoluminescence (PL), scanning electron microscope (SEM), and transmission electron microscope (TEM).

To observe the surface roughness and thickness of a $\mathrm{ZnO}$ film, AFM measurements were conducted (Figure 1(a)). Root mean square (RMS) of $\mathrm{ZnO}$ surface is $\sim 3.3 \mathrm{~nm}$, showing a smooth 
surface with underlying the contact metal. Since surface status has a strong influence on the electrical properties, we can expect that our devices can be operated well [25]. The thickness of the $\mathrm{ZnO}$ film is $\sim 58 \mathrm{~nm}$, hence, our device can be defined as a nano-material based field effect transistor. (Figure 1(b)). The values of RMS and thickness were calculated through Gwyddion program.

Figure 1(c) shows the typical Raman spectrum of the $\mathrm{ZnO}$ film with $473 \mathrm{~nm}$ laser source. The Raman data shows the $\mathrm{E}_{2}$ (high) phonon frequency with respect to that of a $\mathrm{ZnO}$ film, 436 $438 \mathrm{~cm}^{-1}$. The band-gap of $\mathrm{ZnO}$ can be confirmed by photoluminescence (PL) measurement. Figure 1(d) shows the PL data of the $\mathrm{ZnO}$ film with $325 \mathrm{~nm}$ laser source. Usually, the PL spectrum of $\mathrm{ZnO}$ consists of an ultraviolet (UV) emission band ( $\sim 370 \mathrm{~nm}$, narrow band) and a defect-level (DL) emission band (broad band), indicating that the band-gap of $\mathrm{ZnO}$ semiconductor is $\sim 3.4 \mathrm{eV}$. The energy bandgap of the material can be estimated from the UV emission band, while the deeplevel surface defects can be estimated from the DL emission band. In the PL data, the DL emission peak is too weak to be observed, meaning that it has a very small ratio of surface defect density to the total volume. Therefore, we cannot identify the defect-level for the $\mathrm{ZnO}$ film. We calculated the intensity ratio of $\mathrm{I}_{\mathrm{DL}} / \mathrm{I}_{\mathrm{UV}}(\sim 0.11)$ which is much smaller than that of a $\mathrm{ZnO}$ nanowire structure [12].

Figures 2(a) and (b) show high-resolution transmission electron microscopy (HRTEM) images for a Ti-ZnO stack and a ZnO film crystallinity. We observed 50 60 nm thickness of ZnO channel from the image, which is corresponding to the result of the AFM measurement. From the image of the $\mathrm{ZnO}$ film crystal, it was observed that the film consists of poly and single crystal. In the single crystal region, lattice constant is $\sim 0.52 \mathrm{~nm}$ in the structure of a Wurzite structure with a direction of [0001]. Figure 2 (c) exhibits that fast Fourier transform (FFT) of the $\mathrm{ZnO}$ film. The mixed dot and ring pattern is observed from the $\mathrm{ZnO}$ film, showing the combination of poly and single crystal structures. Energy dispersive spectroscopy (EDS) for the $\mathrm{ZnO}$ film was also 
investigated in the supplementary information, showing the peaks for $\mathrm{Zn}$ and $\mathrm{O}$ species (Figure S1).

Figure 2 (d) shows SEM images of completed ZnO TFT with TLM electrode. The scale bar is $200 \mathrm{~nm}$. Each channel (from channel 1 to channel 5) has different channel length for calculation of contact resistance from the TLM method. We used each electrode for the electrical measurement with different channel length. Two different TLM electrodes are exhibited in SEM images; a normal (bottom left) and a saw-shaped (bottom right).

Figures 3(a) and (b) show the electrode shape of the normal electrode and the saw-shaped electrode. We patterned various channel width of $30,40,60,80 \mu \mathrm{m}$. The normal and the sawshaped electrodes were compared with $60 \mu \mathrm{m}$ of channel width as an example. The normal electrode has $60 \mu \mathrm{m}$ of contact line width, which is contacted to the $\mathrm{ZnO}$ channel, while the sawshaped electrode has extended to $\sim 130 \mu \mathrm{m}(60 \mu \mathrm{m}$ and additional $70 \mu \mathrm{m}$, increase in channel width by $\sim 2$ times). It can be expected that increased electrode width provides extended carrier injection line from the source to the $\mathrm{ZnO}$ channel, increasing the carrier transport and drain current value. The difference can be explained by the 3D schematics of band diagrams in Figures 3(c) and (d).

The 3D schematics of band diagram and the difference of carrier injection line for the normal and the saw-shaped electrodes are shown in Figures 3(c) and (d). The normal line electrode has the limited narrow carrier transport path. On the other hand, for a saw-shaped electrode, there is an additional path for carriers from the source to the channel, offering enhanced carrier transport flow. Therefore, it can be expected that additional drain current is achieved from the saw-shaped electrode due to the longer transport line. We theoretically compared the electric field distribution for the normal and the saw-shaped electrodes using high frequency structure simulator (HFSS) in the supplementary information (Figure S2). When the saw-shaped electrode was used, a relatively higher current density was achieved at the contact. To understand if the 
electrode modification can have a benefit on the device performances experimentally, various electrical characterizations were conducted.

Figure 4 (a) displays the transfer characteristics $\left(\mathrm{I}_{\mathrm{DS}}-\mathrm{V}_{\mathrm{BG}}\right)$ of the normal and the saw-shaped electrode $\mathrm{ZnO}$ TFTs. Each measurement was done at room temperature in an ambient air. Drain current was calculated by the following conventional drain current equation.

$$
I_{D S}=\frac{1}{2} \mu_{F E} C_{o x} \frac{W}{L}\left(V_{G}-V_{T H}\right) V_{D}
$$

$\mathrm{I}_{\mathrm{DS}}$ is the drain current, $\mu_{\mathrm{FE}}$ is the field-effect mobility, $\mathrm{C}_{\mathrm{OX}}$ is the oxide capacitance, $\mathrm{W}$ is the channel width, $\mathrm{L}$ is the channel length, $\mathrm{V}_{\mathrm{G}}$ is the gate bias, $\mathrm{V}_{\mathrm{TH}}$ is the threshold voltage, and $\mathrm{V}_{\mathrm{D}}$ is the drain bias. Gate bias was swept ranging from $-30 \mathrm{~V}$ to $30 \mathrm{~V}$ and drain bias was applied at $20 \mathrm{~V}$. The transfer curve shows a typical unipolar n-type behavior with a depletion-mode (Dmode). It is well-known that the majority carrier is electron in $\mathrm{ZnO}$ and the source is oxygen vacancies in the crystal structure. $\mathrm{I}_{\mathrm{ON}} / \mathrm{I}_{\mathrm{OFF}}$ ratio is over $10^{4}$ for both cases, indicating that our $\mathrm{ZnO}$ device has enough switching performance to be used for integrated circuits. Nano-material based transistors including ZnO TFT are Schottky-barrier type transistors which is different with conventional silicon metal-oxíde-transistors (Si MOSFETs) in operations [26-28]. Since the operation of Schottky-barrier type transistors is mostly determined by the status of contact region and barrier height dimension, increasing in contact line length at the junction can has advantages of device performance enhancement. By using the saw-shaped electrode, both $\mathrm{I}_{\mathrm{ON}}$ and $\mathrm{I}_{\mathrm{OFF}}$ increased. Although there is concern about increased standby power, the increase of $\mathrm{I}_{\mathrm{OFF}}$ is much smaller than that of $\mathrm{I}_{\mathrm{ON}} . \Delta \mathrm{I}_{\mathrm{OFF}}$ and $\Delta \mathrm{I}_{\mathrm{ON}}$ is $1.21 \mathrm{pA}$ and $15.1 \mathrm{nA}$, respectively.

Figure 4(b) shows the output characteristics of ZnO TFT with the normal and the sawshaped electrode. During electrical measurements, $30 \mathrm{~V}$ of back-gate bias was applied with drain bias sweep range of $0 \sim 5 \mathrm{~V}$. Drain current was compared with different channel lengths. As expected, drain current increases as channel length reduced. From the output characteristics, the 
In order to compare the normal and the saw-shaped electrodes statistically, average drain current was calculated in Figure 5. Drain current values for devices were normalized with channel length to make a fair comparison. We compared three cases; (i) normal electrode ( $\mathrm{L}_{\mathrm{W}}$ ), (ii) 2 times channel width, $2 \times \mathrm{L}_{\mathrm{w}}$ (calculation), (iii) saw-shaped (experiment). When comparing the theoretical value of $2 \times \mathrm{L}_{\mathrm{w}}$ case and the saw-shaped case, it was expected that 2 times increase in drain current would be achieved with the saw-shaped electrode. However, the drain current increased by $\sim 1.5$ times. This discrepancy can be understood by the calculation of total resistance.

$$
R_{T O T}=R_{C H}+2 R_{C O}
$$

$\mathrm{R}_{\text {TOт }}$ is total resistance, $\mathrm{R}_{\mathrm{CH}}$ is channel resistance, and $\mathrm{R}_{\mathrm{CO}}$ is contact resistance. By using sawshaped electrode, it was expected that $\mathrm{R}_{\mathrm{CO}}$ can be reduced 2 times since contact line between the contact metal and the channel increases, while there is no change of $\mathrm{R}_{\mathrm{CH}}$. The saw-shaped electrode can partially contribute to reduction in $\mathrm{R}_{\text {тот }}$ by reducing $\mathrm{R}_{\mathrm{CO}}$. Even though the saw shape electrode does not show 2 times increase in drain current of the normal electrode, it offers an advantage of $\sim 50 \%$ increase without device area consumption.

A modified saw-shaped electrode offers a benefit of increasing in channel width at the contact junction for carriers to pass through the Schottky-barrier easier. As a result, we could observe the reduction in contact resistance. To calculate contact resistance $\left(\mathrm{R}_{\mathrm{CO}}\right)$, there are several approaches such as transmission line measurement (TLM) and using the ratio of two linear DC curves [29-30]. We could calculate $\mathrm{R}_{\mathrm{CO}}$ from the TLM method with several different channel 
length since large area $\mathrm{ZnO}$ semiconductor area was achieved. $\mathrm{R}_{\mathrm{CO}}$ was estimated at $\mathrm{L}_{\mathrm{CH}}=0 \mu \mathrm{m}$ by an extrapolation method from various resistance values of devices which have different channel lengths (Figure S3).

Figure 6 (a) shows $R_{\text {CO }}$ values for each case from TLM method. Each measurement was conducted at room temperature. $\mathrm{R}_{\mathrm{CO}}$ values were also compared for three cases; (i) normal electrode, $\mathrm{L}_{\mathrm{w}}$, (ii) 2 times channel width, $2 \times \mathrm{L}_{\mathrm{w}}$ (calculated), (iii) saw-shaped (experiment). When we consider 2 times ((ii) $2 \times \mathrm{L}_{\mathrm{W}}$ ) channel width of the normal electrode, calculated $\mathrm{R}_{\mathrm{CO}}$ is reduced to $50 \%$, since the contact line between the contact metal and the channel increases by 2 times. Interestingly, the $\mathrm{R}_{\mathrm{CO}}$ value of the saw-shaped electrode case was also reduced by $\sim 50 \%$, showing $100 \mathrm{M} \Omega \cdot \mu \mathrm{m}$ of $\mathrm{R}_{\mathrm{CO}}$ which is similar value with that of the case of $2 \times \mathrm{Lw}_{\mathrm{w}}$. The results suggest that the saw-shaped electrode offers almost same contact resistance reduction rate compare to the case (2) $(2 \times \mathrm{Lw})$ with a benefit of deyice area efficiency.

Figure 6 (b) shows the average contact resistance as a function of gate bias for the normal and the saw-shaped electrode. The contact resistance has a strong correlation with the back gate bias. The correlation between the gate bias and the contact resistance can be explained by two reasons: (i) a Schottky-barrier at the metal/ZnO junction is determined by the electric field from the gate terminal, modulating carrier tunneling efficiency through the barrier; (ii) the electrical doping which induces a smaller $\mathrm{R}_{\mathrm{CO}}$ in the $\mathrm{ZnO}$ channel can be determined with the gate bias, which is similar phenomena as in graphene [31]. Overall, average $\mathrm{R}_{\mathrm{CO}}$ of the saw shape electrode is lower than that of the normal electrode. Average $\mathrm{R}_{\mathrm{CO}}$ of the normal and the saw-shaped electrode is $\sim 167 \mathrm{M} \Omega \cdot \mu \mathrm{m}$ and $\sim 100 \mathrm{M} \Omega \cdot \mu \mathrm{m}$ at the saturation region (at $\mathrm{V}_{\mathrm{BG}}=30 \mathrm{~V}$ ).

\section{Conclusions}

In summary, we have shown a saw-shaped electrode can increase effective channel width. Additional effective channel width and widened carrier transport region from the source 
to the $\mathrm{ZnO}$ channel were expected from mask design and band diagram. As a result, reduction in contact resistance and increasing in drain current were observed with the saw-shaped electrode.

\section{Acknowledgements}

This publication is based upon work supported by the King Abdullah University of Science and Technology (KAUST) Office of Sponsored Research (OSR) under Award No. Sensor Innovation Initiative OSR-2015-Sensors-2707 and KAUST-KFUPM Special Initiative OSR2016-KKI 2880. 


\section{References}

[1] Cha S H, Oh M S, Lee K H, Im S, Lee B H and Sung M M 2008 Appl. Phys. Lett. 92 023506

[2] Jun J H, Park B, Cho K, and Kim S 2009 Nanotechnology. 20505201

[3] Yang C, Hong K, Jang J, Chung D S, An T K, Choi W-S, and Park/C E 2009 Nanotechnoogy 20465201

[4] Elzwawi S, Hyland A, Lynam M, Patridge J G, McCulloch D G and Allen M W 2015 Semicond. Sci. Technol. 30024008

[5] Huang H-C and Hsieh T-E 2010 Nanotechnoogy 21295707

[6] Park I-J, Jeong C-Y, Cho I-T, Lee J-H, Cho E-S, Kwon S J, Kim B, Cheong W-S, Song S-H and Kwon H-I 2012 Semicond. Sci. Technol. 27105019

[7] Chang S, Song Y W, Lee S, Lee S Y and Ju B K 2008 Appl. Phys. Lett. 92105019

[8] Gandla S, Gollu S R, Sharma R, Sarani V and Gupta D 2015 Appl. Phys. Lett. 107 105019

[9] Hanna A N, Hussain A, Omran H, Alsharif S M, Salama K N and Huaain M M 2016 IEEE. Trans. Electron. Dev. 631550

[10] Park C H, Lee G, Lee K H, Im S, Lee B H and Sung M M 2009 Appl. Phys. Lett. 95 153502

[11] Hanna A N, Ghoneim M T, Bahadry R R, Hussain A M and Hussain M M 2013 Appl. Phys. Lett. 103224101

[12] Park W, Jo G, Hong W-K, Yoon J, Choe M, Lee S, Ji Y, Kim G, Kahng Y H, Lee K, Wang D and Lee T 2011 Nanotechnology 22205204

[13] Tarish S, Xu Y, Wang Z, Mate F, Al-Haddad A, Wang W and Lei Y 2017 Nanotechnology 28405501

[14] Noh S H, Choi W, Oh M S, Hwang D K, Lee K, Im S, Jang S and Kim E 2007 Appl. Phys. Lett. 90253504

[15] Simanjuntak F M, Chandrasekaran S, Pattanayak B, Lin C-C and Tseng T-Y 2017 Nanotechnology 28 38LT02

[16] Hasan G M, Banna U and Park I-K 2017 Nanotechnology 28445402

[17] Chen S M and Wang S S 2014 Appl. Phys. Lett. 105223304 
[18] Hwang C S, Park S H K, Oh H, Ryu M K, Cho K I and Yoon S M 2014 IEEE Electron. Device. Lett. 35360

[19] Petti L, Aguirre P, Munzenrieder N, Salvatore G A, Zysset C, Frutiger A, Buthe L, Vogt C and Troster G 2013 IEEE International Electron Devices Meeting (2013 IEDM) 296

[20] Hsieh H H and Wu C C 2006 Appl. Phys. Lett. 89041109

[21] Agrawal A, Lin J, Barth M, White R, Zheng B, Chopra S, Gupta S, Wang K, Gelatos J, Mohney S E and Datta S 2014 Appl. Phys. Lett. 104112101

[22] Liu H, Neal A T and Ye P D 2012 ACS Nano 68563

[23] Noori A M, Balseanu M, Boelen P, Cockburn A, Demuynck S, Felch S, Gandikota S, Gelatos A J, Khandelwal A, Kittl J A, Lauwers A, Lee W C, Leí J X, Mandrekar T, Schreutelkamp R, Shah K, Thompson S E, Verheyen P, Wang C Y, Xia L Q and Arghavani R 2008 IEEE Trans. Electron. Dev. 551259

[24] Mueller T, Xia F N A and Avouris P 2010 Nat. Photonics. 4297

[25] Park W, Jo G, Hong W K, Yoon J, Choe M, Lee S, Ji Y, Kim G, Kahng Y H, Lee K, Wang D L and Lee T 2011 Nanotechnology 22205204

[26] Brillson L J and Lu Y C 2011 J. Appl. Phys. 109121301

[27] Lu M Y, Lu M P, You S J, Chen C W and Wang Y J 2015 Sci. Rep. 515123

[28] Zhang X A, Hai F S, Zhang T, Jia C H, Sun X W, Ding L H and Zhang W F 2012 Microelectron. Eng. 935

[29] Campbell J P, Cheung K P, Suehle J S and Oates A 2011 IEEE Trans. Electron. Dev. 321047

[30] Yang L M, Majumdar K, Du Y C, Liu H, Wu H, Hatzistergos M, Hung P Y, Tieckelmann R, Tsai W, Hobbs C and Ye P D 2014 IEEE Symposium on VLSI Technology DOI: 10.1109/VLSIT.2014.6894432

[31] Xia F N, Perebeinos V, Lin Y M, Wu Y Q and Avouris P 2011 Nat. Nanotechnol. 6 179 


\section{Figure captions}

Figure 1 AFM images showing (a) root mean square (RMS) value of $\mathrm{ZnO}$ film surface and (b) $\mathrm{ZnO}$ film thickness. The RMS and the thickness are estimated as $\sim 3.266 \mathrm{~nm}$ and $\sim 58 \mathrm{~nm}$, respectively. (c) Raman spectrum for $\mathrm{ZnO}$ film showing $\mathrm{E}_{\mathrm{g}}(\mathrm{high})$ peak. The laser source of 473 nm was used (d) Photoluminescence (PL) data for $\mathrm{ZnO}$ film with $325 \mathrm{~nm}$ of laser source. It has ultra-violet (UV) emission band and deep-level (DL) emission band. Band-gap of ZnO can be estimated $\sim 3.4 \mathrm{eV}$.

Figure 2 HRTEM for (a) a Ti-ZnO stack and (b) ZnO crystallinity. (c) Fast Fourier transform (FFT) pattern for a ZnO film. (d) SEM image of a ZnO TFT with TLMelectrode. Normal (bottom left) and saw-shaped (bottom right) are exhibited in the SEM images.

Figure 3 Thin film transistor structure from the top view and electrode shape of (a) the normal and (b) the saw-shaped electrode. 3D schematics of band diagram for (c) the normal and (d) the saw-shaped electrode.

Figure 4 (a) Transfer curves $\left(\mathrm{I}_{\mathrm{DS}}-\mathrm{V}_{\mathrm{BG}}\right)$ measured with a gate bias sweep range from $-30 \mathrm{~V}$ to $30 \mathrm{~V}$ at a fixed drain voltage of $20 \mathrm{~V}$ for a ZnO TFT made with the normal electrode (black dashed line) and ZnO TFT made with the saw-shaped electrode (blue solid line). ZnO TFTs show the typical n-type depletion-mode behavior. (b) Output curves $\left(\mathrm{I}_{\mathrm{DS}}-\mathrm{V}_{\mathrm{DS}}\right)$ for ZnO TFTs with the normal and the saw-shaped electrode. 
Figure 5 Statistical average drain current for (1) normal $\left(\mathrm{L}_{\mathrm{w}}\right)$, (2) $2 \mathrm{~L}_{\mathrm{w}}$ (calculated), and (3) sawshaped electrode (experiment). Each drain current was normalized to give a fair comparison. The saw-shaped electrode offers a benefit of $\sim 50 \%$ of drain current increase.

Figure 6 (a) Total resistance as a function of the channel length for (1) normal $\left(\mathrm{L}_{w}\right),(2) 2 \mathrm{~L}_{w}$ (calculated), and (3) saw-shaped electrode (experiment). The saw-shaped electrode shows $\sim 50$ $\%$ reduction of the normal electrode in contact resistance (b) Average contact resistance as a function of the back gate bias for the normal and the saw-shaped electrode. 

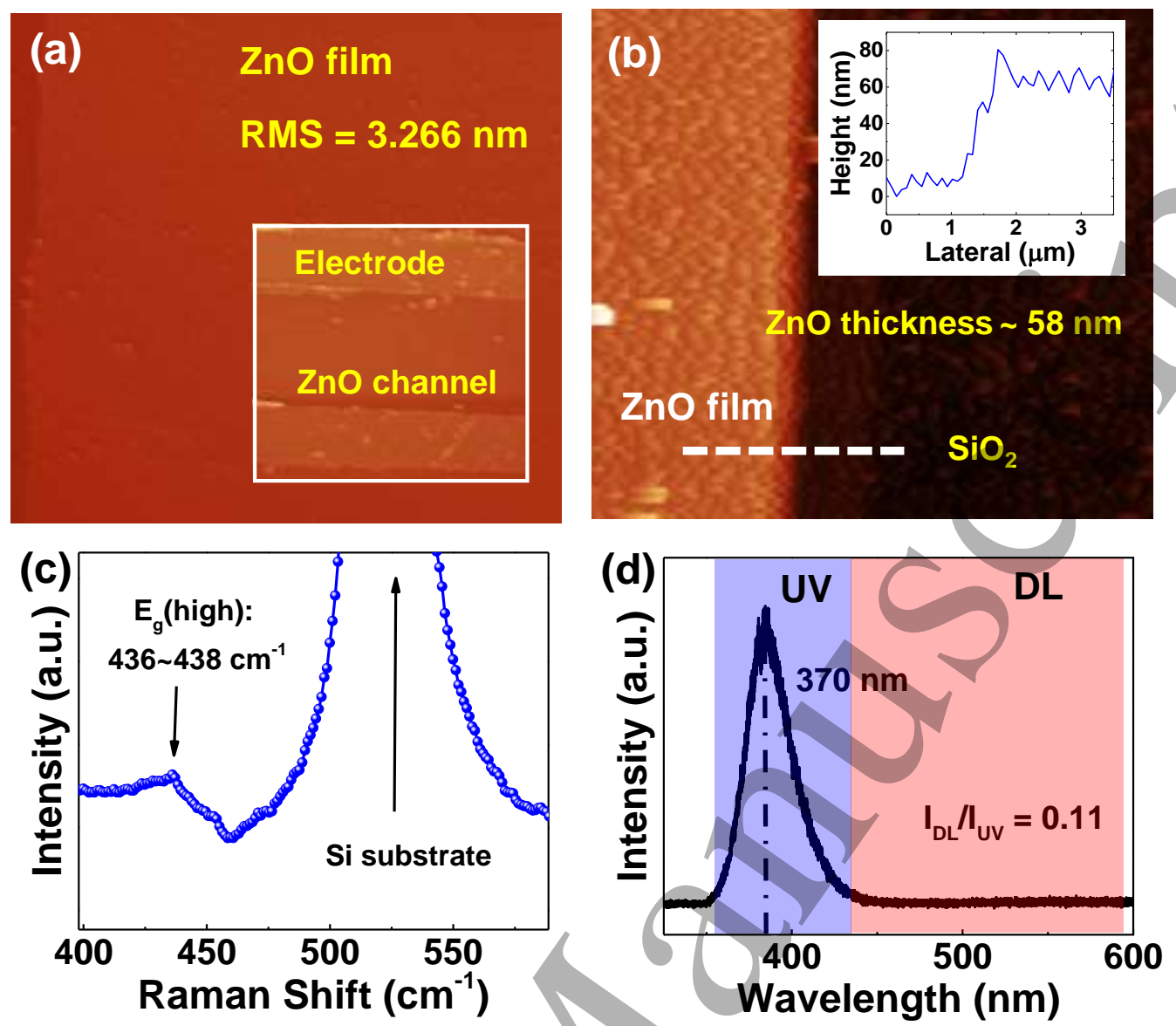

Fig. 1 Park et al. 

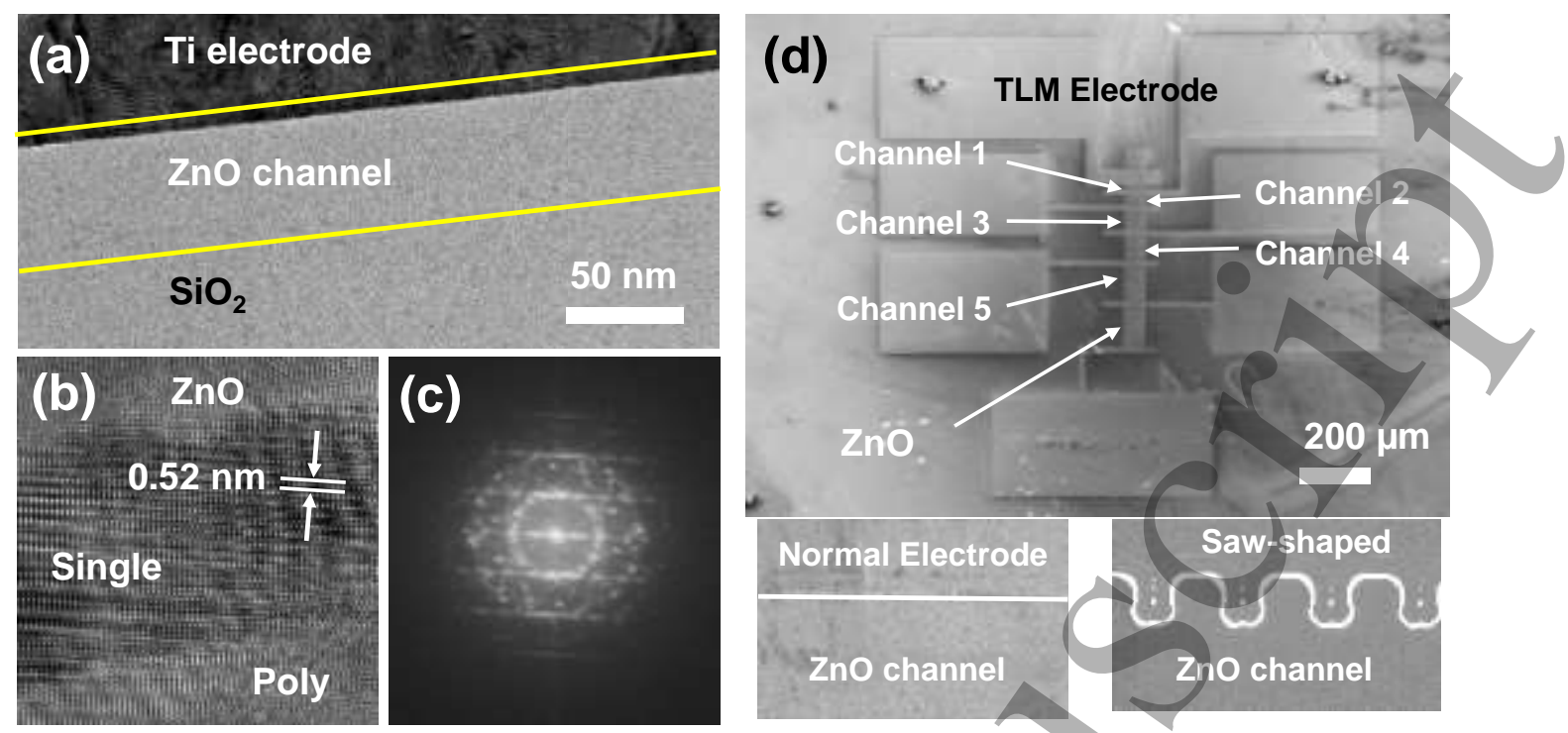

Fig.2 Park et al. 

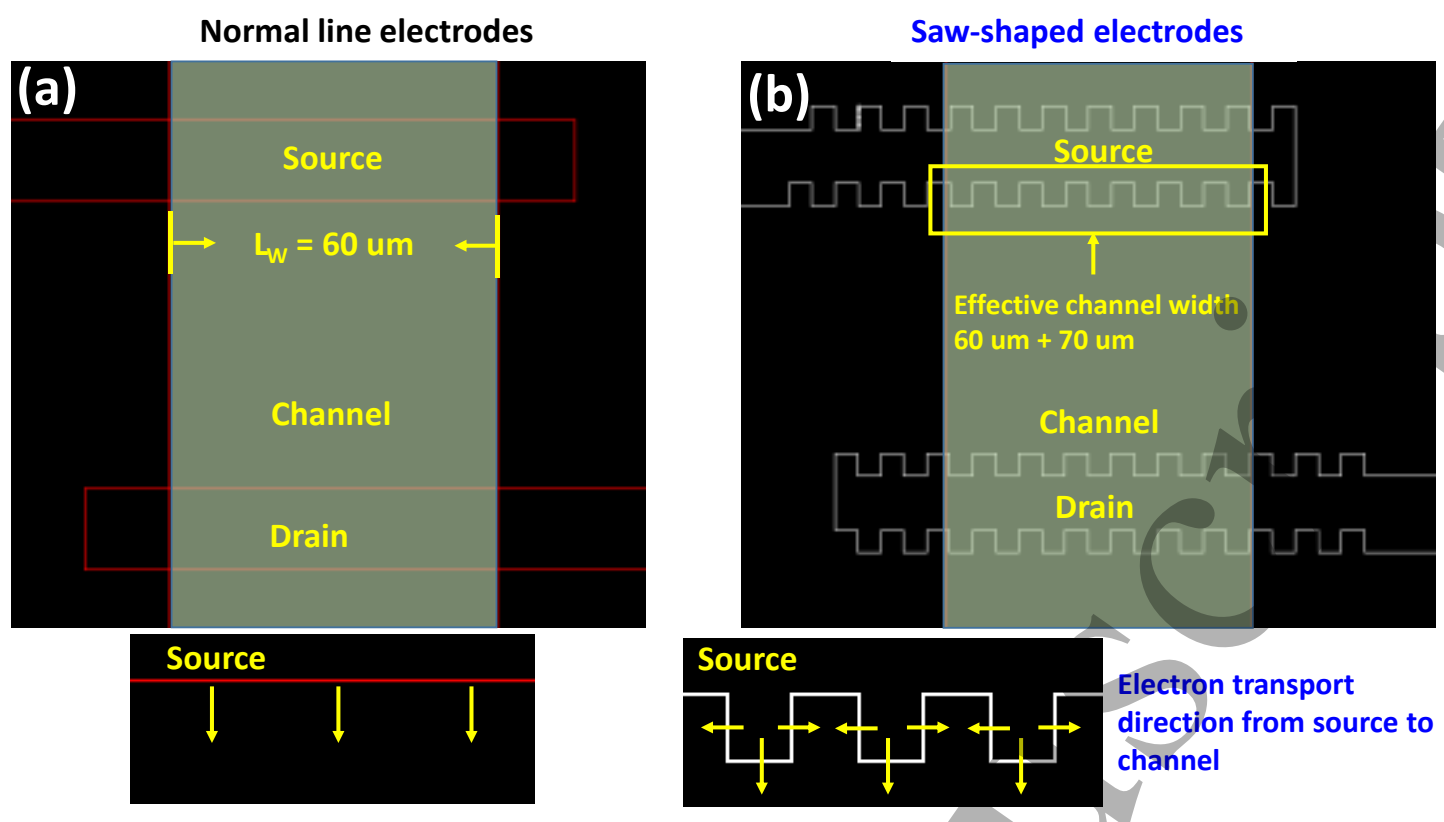

(c)

Fig.3 Park et al.

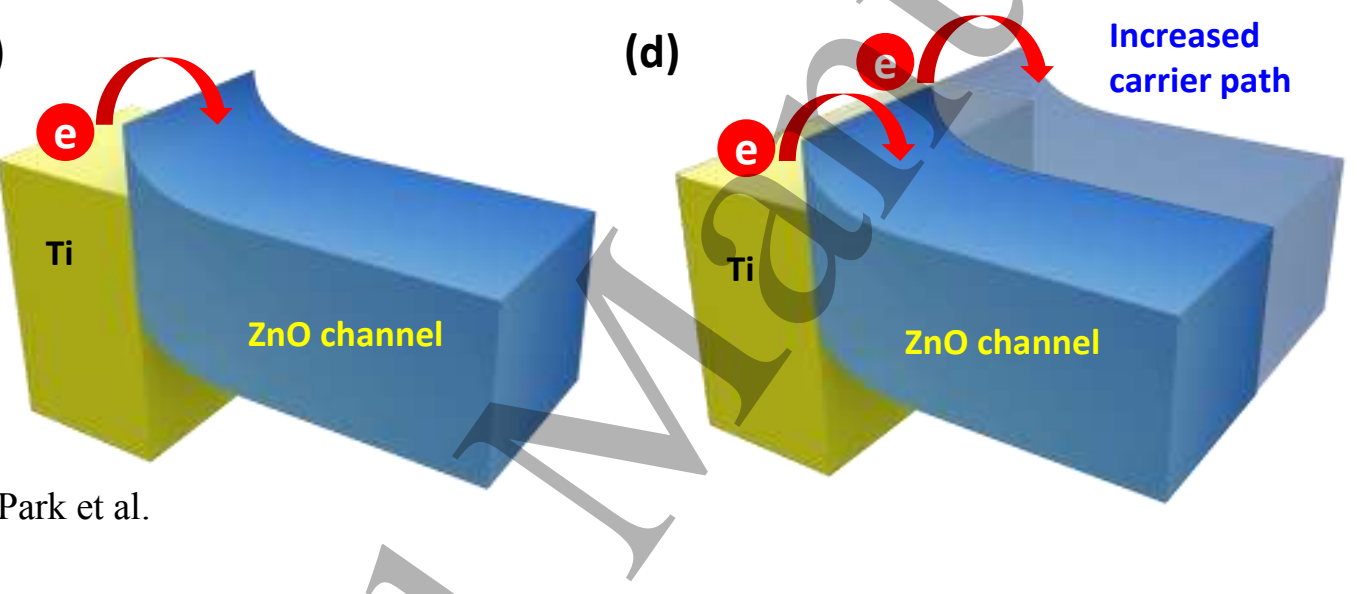



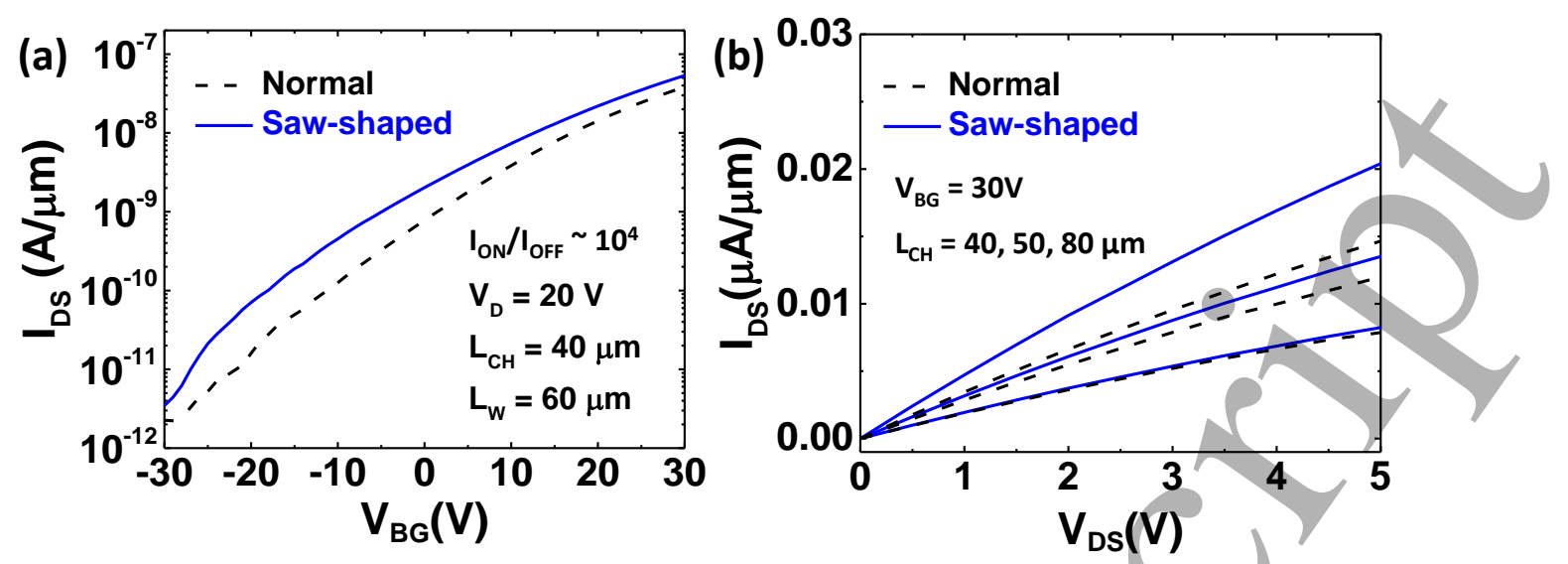

Fig.4 Park et al. 


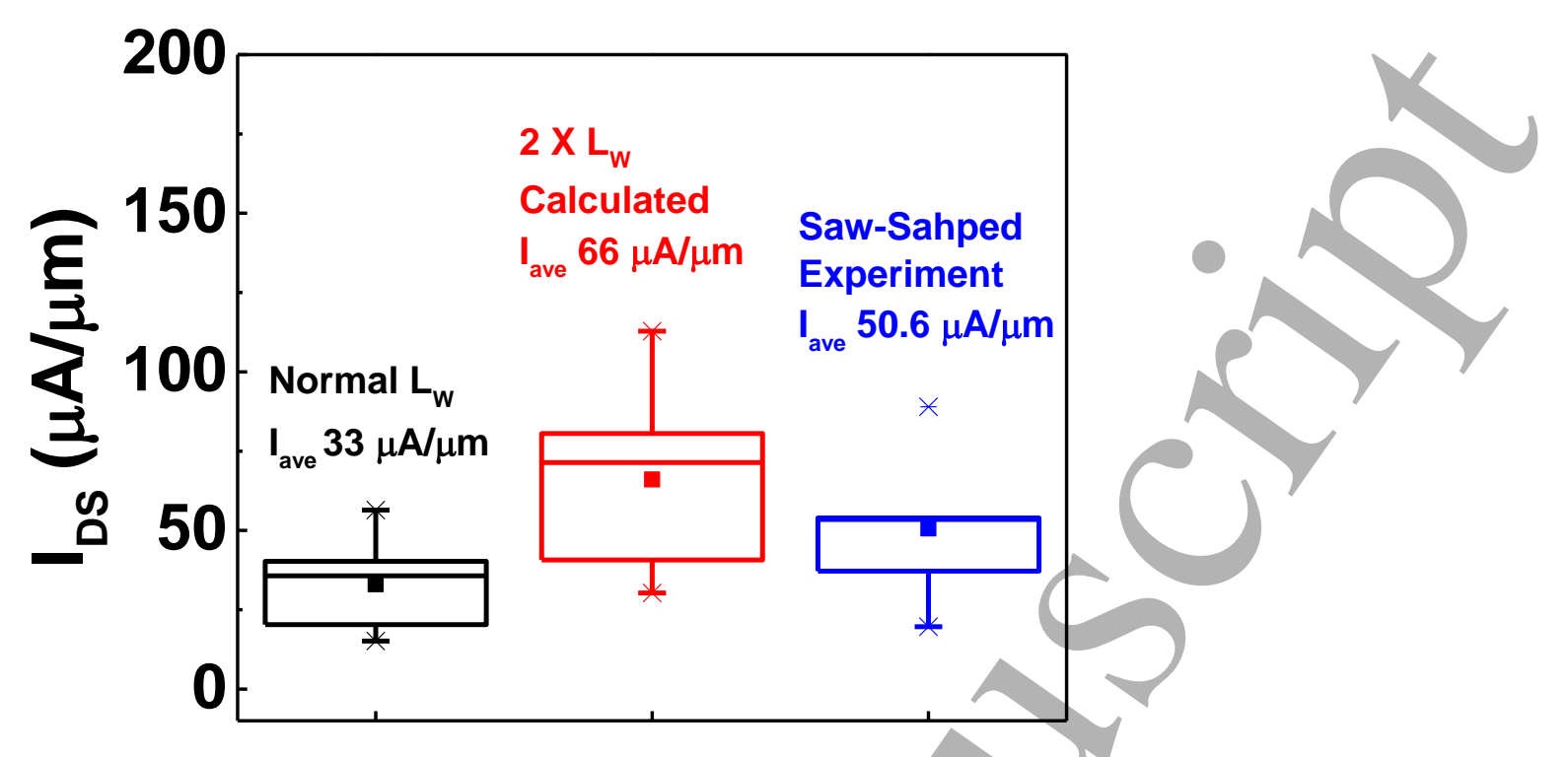

Fig. 5 Park et al. 

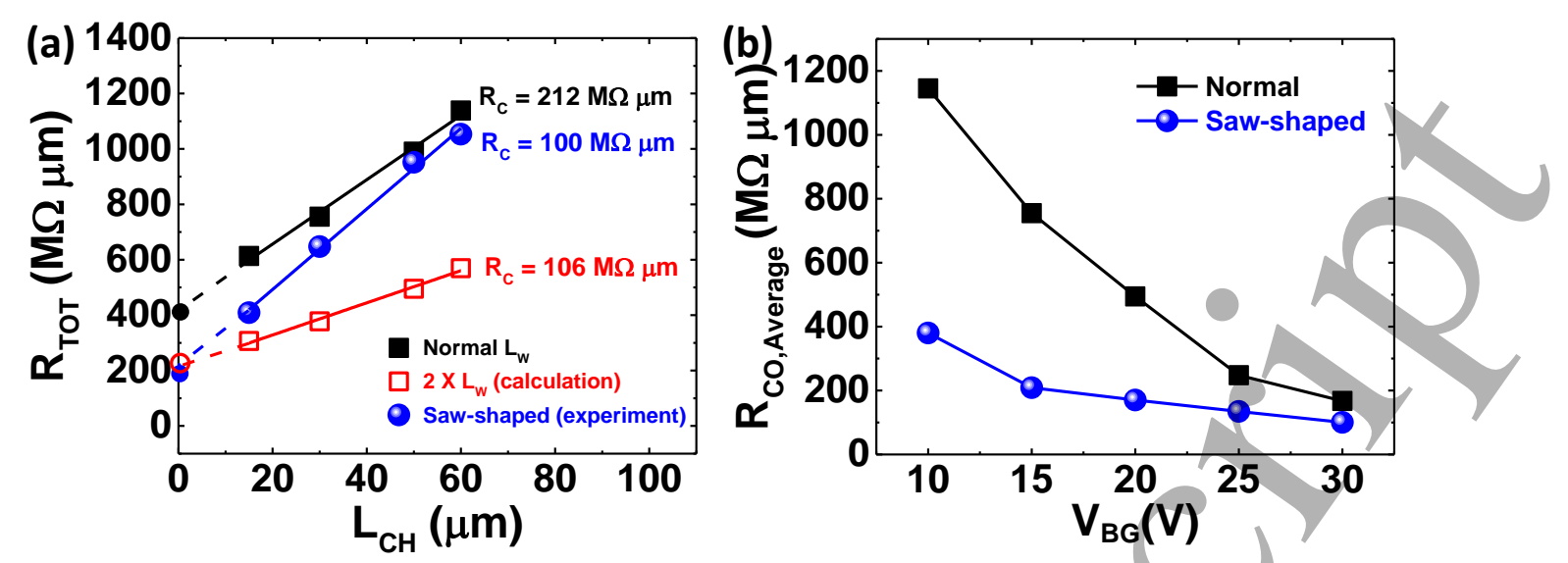

Fig. 6 Park et al. 